This item was submitted to Loughborough's Research Repository by the author.

Items in Figshare are protected by copyright, with all rights reserved, unless otherwise indicated.

\title{
Searching for realism, structure and agency in Actor Network Theory
}

PLEASE CITE THE PUBLISHED VERSION

http://dx.doi.org/10.1111/j.1468-4446.2008.00203.x

\section{PUBLISHER}

Blackwell Publishing Ltd @ London School of Economics and Political Science

\section{VERSION}

AM (Accepted Manuscript)

\section{LICENCE}

CC BY-NC-ND 4.0

\section{REPOSITORY RECORD}

Elder-Vass, Dave. 2019. "Searching for Realism, Structure and Agency in Actor Network Theory". figshare. https://hdl.handle.net/2134/13269. 
This item was submitted to Loughborough's Institutional Repository (https://dspace.lboro.ac.uk/) by the author and is made available under the following Creative Commons Licence conditions.

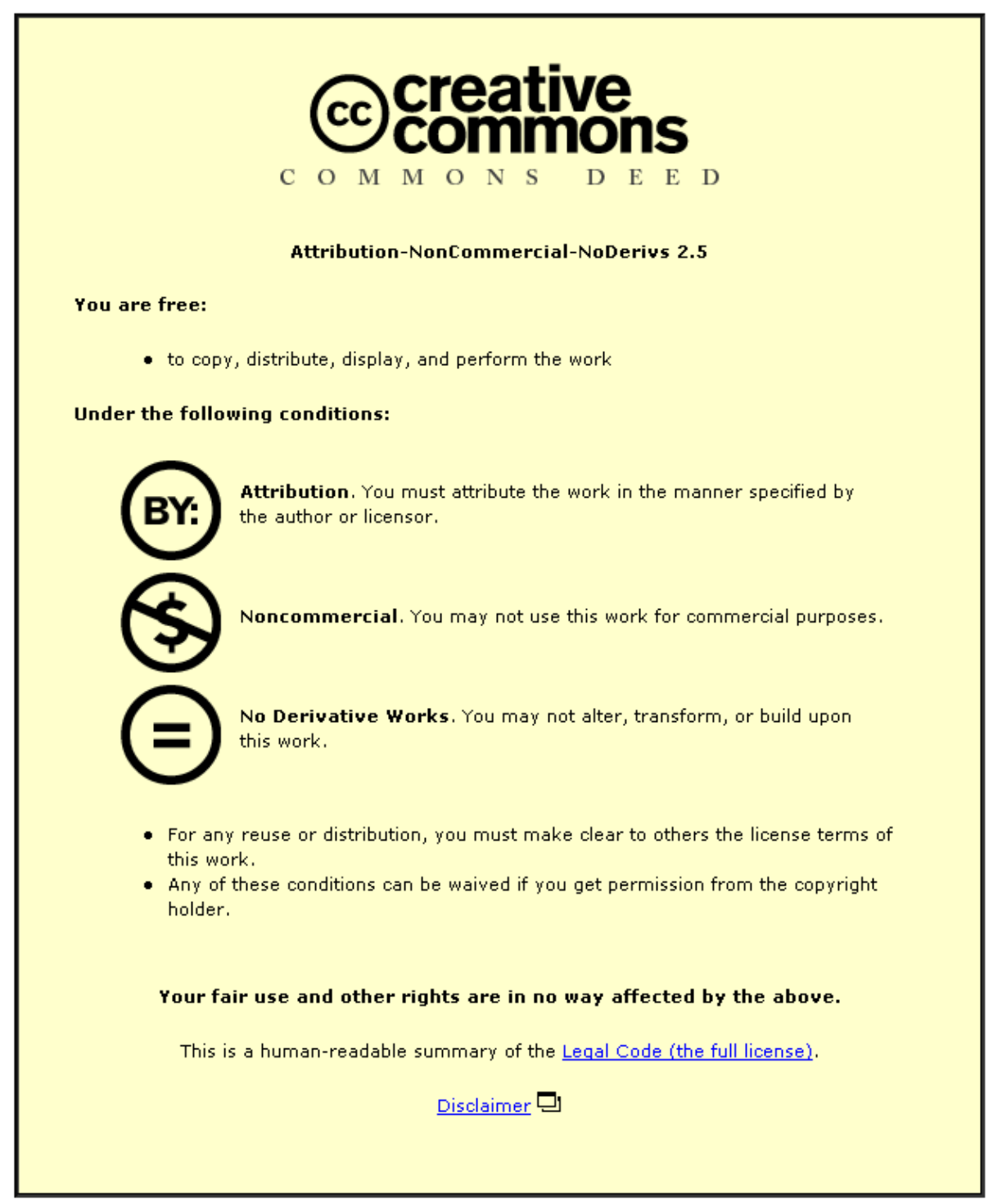

For the full text of this licence, please go to: http://creativecommons.org/licenses/by-nc-nd/2.5/ 


\section{Searching for realism, structure, and agency in Actor Network Theory}

\section{Dave Elder-Vass}

[Note: This is an electronic version of a paper published in the British Journal of

Sociology. Please cite as: Elder-Vass, D. (2008) 'Searching for realism, structure and agency in actor network theory'. British Journal of Sociology 59:3, 455-73.

(C) 2010 London School of Economics and Political Science.] 


\title{
Searching for realism, structure, and agency in Actor Network Theory
}

\begin{abstract}
Superficially, Actor Network Theory (ANT) and critical realism (CR) are radically opposed research traditions. Written from a realist perspective, this paper asks whether there might be a basis for finding common ground between these two traditions. It looks in turn at the questions of realism, structure, and agency, analysing the differences between the two perspectives and seeking to identify what each might learn from the other.

Overall, the paper argues that there is a great deal that realists can learn from actor network theory; yet ANT remains stunted by its lack of a depth ontology. It fails to recognize the significance of mechanisms, and of their dependence on emergence, and thus lacks both dimensions of the depth that is characteristic of critical realism's ontology. This prevents ANT from recognizing the role and powers of social structure; but on the other hand, realists would do well to heed ANT's call for us to trace the connections through which structures are constantly made and remade. A lack of ontological depth also underpins ANT's practice of treating human and nonhuman actors symmetrically, yet this remains a valuable provocation to sociologists who neglect non-human entities entirely.
\end{abstract}

Keywords: Actor network theory; critical realism; social structure; agency 


\section{Searching for realism, structure, and agency in Actor Network Theory ${ }^{1}$}

As a critical realist, it is difficult to read the work of actor network theorists without bridling at some of the common assertions that characterise the research tradition. Most fundamentally, perhaps, the originators of actor network theory (ANT) launched the tradition with a book which argues that science creates the realities it describes (Latour and Woolgar 1979), whereas critical realism (CR) itself was launched with the claim that science is only meaningful because the deepest level of reality exists independently of science and scientists (Bhaskar 1978). Secondly, the constant insistence of actor network theorists on tracing the connections between individual actors instead of accepting the causal role of social structures seems to imply a rejection of the structural moment in sociology that has been stressed by both Roy Bhaskar and Margaret Archer (Bhaskar [1979] 1998; Archer 1995). And thirdly, even actors are treated in a way that seems thoroughly inconsistent with the realist view: human and non-human actors are quite deliberately treated as causally equivalent, whereas realists have portrayed human agents as the unique possessors of a characteristic range of identities and causal powers, with the result that they must be treated quite differently from non-human objects with their own distinctive properties and powers (Archer 2000; Archer 2003).

At least some of these provocative stances may be intended in the spirit of Garfinkel's methodological technique of disrupting our background understandings in order to reveal them to us (Garfinkel 1967: ch. 2). If so, the appropriate response is to set aside any initial hostility, to examine what lies behind them, and to ask whether there might instead be common ground between these two traditions. This paper seeks to do this in turn for the questions of realism, structure, and agency, analysing the differences between the two perspectives and seeking to identify what each might learn from the other. To anticipate the conclusion, I will argue that there is more common ground than might at first appear, and indeed there are valuable lessons that these two traditions can learn from each other, but there are also fundamental ontological differences and so it would be unrealistic to expect outright convergence.

Before going further, however, it is necessary to qualify any assumption of homogeneity within each of these traditions. Within critical realism there are those 
who adhere to the scientific realism of Bhaskar's early work, those who adopt his later dialectical critical realism, and those who advocate the more spiritual views expressed in his most recent work (Dean, Joseph and Norrie 2005). Amongst realists in sociology, and perhaps the social sciences in general, the first group are decisively in the majority and I shall assume that such a view is representative of critical realism in general in this paper. I am less well placed to make judgments on divergent tendencies within actor network theory. I shall rely primarily on the work of Bruno Latour and John Law. Despite their desire to deny essentialism and to apply this denial to ANT itself (Law 1999), I for one have not found any great discrepancies between these thinkers, and even their 'after actor network theory' seems continuous with earlier actor network theory. Still, there are no doubt heterogeneities within this tradition that I have neglected. ${ }^{2}$

\section{Realism and science}

ANT's claim that science makes the realities it describes is one of the central arguments of Latour and Woolgar's seminal Laboratory Life. Using the term 'outthere-ness' to refer to external reality, they argue that 'out-there-ness is the consequence of scientific work rather than its cause' (Latour and Woolgar 1986: 182).

As Law puts it,

they are telling us that it is not possible to separate out (a) the making of particular realities, (b) the making of particular statements about those realities, and (c) the creation of instrumental, technical, and human configurations and practices, the inscription devices that produce these realities and statements. Instead, all are produced together (Law 2004: 31).

And just to make sure his meaning is clear, Law tells us: 'Let me emphasise that: realities are being constructed', though he goes on immediately to stress that it is not people that construct these realities, but the practices of science. But both Latour and Law also insist that, unlike some varieties of social constructionism, actor network theory is also realist about the existence of external reality. Out-there-ness may be constructed, but it is still out-there, and not just in our heads. Law, for example, writes,

what I am arguing is not a version of philosophical idealism. I am not saying that since the world defies any overall attempt to describe and understand it, we can therefore realistically believe anything about it we like (Law 2004: 7-8). 
And Latour has explicitly disavowed any connection with the more extreme versions of social constructionism, in which social constructions are arbitrary and 'not true' (Latour 2005: 88-90). Although science is a process of the construction of facts, its products nevertheless are facts - 'the most ascertained, objective, and certified results ever obtained by collective human ingenuity' (Latour 2005: 89-90).

On the other hand, Law has argued that ANT is committed to a rather different conception of the real than common-sense realism. Beyond the simple belief in 'outthereness' which we might call primitive realism, he identifies a series of other common-sense beliefs about reality, including independence - that 'external reality is usually independent of our actions and especially of our perceptions' - and anteriority - that external reality precedes us (Law 2004: 24-5). He claims that, 'realism and critical realism are committed, at least in general, to the... anteriority, [and] independence... of the real, as well as its primitive and originary versions' (Law 2004: 58). By contrast, for actor network theory, reality is usually independent of individuals, but not of scientific practices, and it is usually not anterior to us, though science produces a hinterland of devices and practices which become anterior to subsequent science (Law 2004: 31-2).

At first sight, this would seem to conflict with the foundational argument of critical realism, Bhaskar's assertion that 'It is a condition of the intelligibility of experimental activity that in an experiment the experimenter is a causal agent of a sequence of events but not of the causal law which the sequence of events enables him to identify' (Bhaskar 1978: 12).

Bhaskar argues that reality may be divided into three domains: the empirical, the actual, and the real. The empirical consists of that which is experienced - those events and things that are observed by humans. This is a subset of the actual - that which occurs - and the domain of the actual is populated by events and things (or, as I shall call them, entities) which may or may not be observed. The actual is in turn a subset of the real, which also includes the mechanisms that give rise to causal laws, and it is these mechanisms that necessarily pre-exist the scientist. Mechanisms arise from the structure of entities, and give them causal powers, also known as emergent properties (Bhaskar 1978: 14). Events are caused by the interaction of a variety of mechanisms, and the job of the scientist is to arrange empirical events in the course of an experiment so as to isolate the action of a single mechanism and thus identify it. ${ }^{3}$ 
The distinction between the empirical, the actual, and the real provides a dimension of depth to CR's ontology (we will come to a second dimension of depth ontology in the section on structure).

Thus, on the one hand, actor network theorists claim that science produces the realities it describes, and on the other, critical realists argue that science only makes sense if it is oriented to the discovery of powers and mechanisms that exist independently of it (and prior to it). We can begin to reduce the apparent contradiction by examining more carefully the nature of the 'realities' produced by science. Critical realism is perfectly consistent with the argument that science (taken as a complex interaction of scientists, social practices, organizations, and material devices) is capable of producing realities of certain kinds. We can only understand the real point of difference between the two traditions by making clear which kinds of reality each of them sees science as producing.

For realists, then, it is perfectly acceptable to argue that science produces:

- Material records of its results, including for example figures and graphs on pieces of paper, and data in computer systems;

- Theories, hypotheses, models, explanatory texts, and systems of scientific belief;

- devices based on and instrumentalising its theory; ${ }^{4}$ and

- $\quad$ some of the particular actual entities used in its experiments - an animal behaviour laboratory might breed its own rats, for example, and manufacture the maze through which they are forced to pass.

What the experiment does not and can not produce, however, is the mechanism being tested. Indeed, if it did so, there would be no point in the experiment; this is where Bhaskar's insight comes in - science gets its meaning from the belief that there are such mechanisms that exist independently of the experimental environment, and the point of the experimental environment is to prompt the exercise of these mechanisms. This particular reality, then - the mechanism being tested - is not produced by science; all that science produces is knowledge about this aspect of reality.

A further qualification, in two stages, is necessary here, which arises from the argument that mechanisms are carried by actual entities. First of all, I have already made clear that mechanisms are implemented by entities, and so it might seem that in 
creating the entities - say rats - that implement a mechanism, we are creating the mechanism itself. It would be more accurate to say, however, that in creating the rats we are actualizing the mechanism: we are creating an actual entity that carries the mechanism, but we are not creating the real mechanism. The real mechanism, for Bhaskar, is the way that a certain type of thing acts, producing a tendency for things of this type to create certain sorts of effects; it is not the actual acting of an actual instance of the thing. What precedes science, then, is not particular actualizations of the mechanism, but the fact that if a thing of this particular type is ever created, it will possess the powers arising from the mechanism.

A similar argument applies at the second stage. We might argue, for example, that a laboratory might not just produce rats that actualize some pre-existing rat mechanism, but it might innovate in the production of rats. It might genetically engineer its rats so as to produce animals with an entirely new capability. Rats that can leap over buildings, rats that can fly, rats that can see through concrete walls - let your imagination run wild! Let us say that no rats have ever before had this genetic structure, this mechanism, or this capability. Would this mean that the laboratory had produced a new mechanism, one that did not precede the scientists concerned?

Once again, there is a sense in which this is true, but there is still a sense in which it is not: it was always the case that if a rat appeared with this genetic structure, whatever the causal history leading to this, then it would have the potential to develop this new capability. This mechanism may never have been actualized before the rats were modified, but it was always the case that it would occur if this particular configuration of entities was somehow produced. This is the aspect of reality that scientists can never make; they can only ever find out about it. This is the aspect that is always and necessarily anterior to human intervention.

This reality, however, is one that does not 'actually' exist. It may be independent, anterior, definite, and singular, but it is not 'out-there'. And so it cannot be captured by an actualist understanding of reality. This is perhaps counter-intuitive, but it is not a contradiction. It really is these mechanisms that scientists are trying to discover in their experiments, much of the time, and it really is the presumed existence of such mechanisms that makes science make sense. We might query the use of the term 'real' to describe these non-actual mechanisms, but the terminology is 
of little importance; it is the fact that such mechanisms are implicit in the nature of the universe, whether (and before) we seek to actualize them, that makes them important.

It is because these mechanisms can be actualized in two ways that science is possible and worthwhile: they can be actualized in the entities that possess and sometimes exercise them; and they can be actualized (fallibly) in a different sense in the theories that we use to describe them. Both of these actualizations may be produced by science; but the underlying mechanism may not.

At this stage we might attempt a synthesis: in realist terminology (because ANT does not have the terminology to make this distinction), critical realism could accept that science produces actualities of all kinds, though not all particular instances of the actual; and actor network theory could accept that real mechanisms are never produced by science. In Law's terms, real mechanisms are always anterior and independent; but, ironically, they may not be out-there, if out-there refers to the actual, as I suspect it does. If ANT identifies reality with the actual out-there, as it would seem to do in the absence of a depth ontology, this would help to explain why it overlooks real mechanisms when it argues that science can create realities.

\section{Statements about being, statements about knowledge}

It remains to be seen whether actor network theorists (or indeed other critical realists) would take kindly to such a suggestion. Latour's rejection of extreme constructionism and Law's rejection of philosophical idealism encourage optimism; but on the other hand there are numerous instances in which actor network theorists still make claims that critical realists would find hard to accept.

Latour, for example, argues that 'Galileo may have constructed the phases of Venus, but once that construction was complete her phases appeared to have been “always already present" ' (Latour 1996: 23). Similarly, Annemarie Mol, in discussing medical diagnoses of the condition atherosclerosis, argues that the condition does not exist until a doctor diagnoses it (Law 2004: 46), and indeed that if there are multiple medical departments diagnosing it in different ways, then there are 'multiple atheroscleroses' (Law 2004: 50). Paradoxically, however, 'this does not imply that the doctor brings [the patient's] disease into being' (Mol 2002; quoted in Law 2004: 46). 
Now, although all of these statements refer to actualities rather than mechanisms, the critical realist acknowledgement that science can create actualities does not extend to these cases. For critical realists, the phases of Venus existed in actuality before they were empirically recognized, and a patient's arteries are furred up (or not) before, or whether, they are diagnosed as such. In each case, of course, the labels that we attach to these events are constructed by people, and in each case it may be impossible for us to recognize or discuss these events without the construction of science or narrative, but for realists the description of such actualities is entirely distinct from the question of whether they exist; and in each of these cases, the actuality concerned exists independently of, and anterior to, the act of their description.

To believe otherwise is to commit what Bhaskar calls the epistemic fallacy, the belief 'that statements about being can always be transposed into statements about our knowledge of being' (Bhaskar 1978: 16). In each of these cases, ANT denies not only the separation of the real from the actual, but the separation of the actual from the empirical: the implication is that 'out-there' does not exist until it has been identified and described. Existence independent of our knowledge of it is thus denied.

ANT, however, has a counter argument (though one that is not to my knowledge explicitly counterposed by them to Bhaskar's position) that represents almost a mirror image of this critique. Latour and Woolgar argue that scientific statements can be divided into unconditional claims that are taken to be true, and perhaps even taken for granted, and statements that are qualified with what they call modalities. Modalities qualify statements by specifying particular contexts or sources for them - for example, pointing out that a claim is made by $x$, on the basis of an experiment reported in journal y (Latour and Woolgar 1986: 77-9). Such modalities are read as casting doubt on the truth of the claim; the claim is not yet well enough established to merit unconditional reporting, so its provenance must be stated, with the implication that it may still be undermined. One objective of scientists, then, is to persuade other scientists that their own claims are well enough established to drop such qualifications, to drop or delete the modalities (Law 2004: 27-8; Latour and Woolgar 1986: 81). This demodalization deletes all references to the hinterland of subjectivity, experiment, and prior theory to leave an unqualified statement that therefore appears to relate purely to the external world that exists independently of 
science. Now, what was previously a statement about a scientific claim made by particular people for particular reasons becomes a statement about independent reality. 'Before long, more and more reality is attributed to the object and less and less to the statement about the object. Consequently, an inversion takes place: the object becomes the reason why the statement was formulated in the first place' (Latour and Woolgar 1986: 177).

Here, then, there is an implicit reversal of Bhaskar's position: in a sense they are arguing that statements about reality are a kind of ontic fallacy: they are statements about what we claim to know about reality and how we know it, that have been stripped of the 'who' and the 'how' until they appear to be statements about reality itself. From this perspective, all statements about being have already been transposed from statements about our knowledge of being. From this perspective, the fallacy is to forget that demodalized statements are dependent and conditional upon the scientific work that went before.

We seem to have arrived at a stand-off here: epistemic fallacy vs. ontic fallacy. But are these two positions inherently contradictory? The argument that all unconditional scientific statements are demodalized need not lead to the conclusion that they are not true, or justified. Indeed, the actor network theorists do not themselves come to such a conclusion; for them, as we have seen, demodalized statements remain 'the most ascertained, objective, and certified results every obtained by collective human ingenuity' (Latour 2005: 89-90). And they remain statements about external reality. Nor need Bhaskar deny that scientific statements are arrived at through a process of modalization and demodalization, because he makes no claim to the infallibility of scientific statements about reality. On the contrary, he recognizes that all such claims have the status of knowledge, and that all human knowledge is fallible. All that he wants to deny is the argument that we cannot make claims about external reality. On reflection, then, despite appearing contradictory, these metaphysical arguments may be entirely consistent.

What does pose an obstacle is the multiplication of cases in which ANT appears to deny common sense realism: such as the phases of Venus that did not exist before Galileo discovered them and the arteries furred only when a doctor diagnoses them. These seem to illustrate a second level at which ANT fails to see the need for the first dimension of Bhaskar's depth ontology: the need to distinguish the empirical 
from the actual, and to recognize that things may actually exist before we observe them. If this is really something that ANT agrees on, it poses a potentially insuperable obstacle to reconciliation with critical realism.

\section{Social Structure in Critical Realism}

There is also a second dimension of depth in Bhaskar's ontology: the recognition that reality is stratified into an ontological hierarchy of entities, in which higher level entities have emergent properties - properties not possessed by the lower level entities that are their parts. This dimension of depth is closely interwoven with the first: it is the mechanisms that we find in the domain of the real that are responsible for emergent properties, which are synonymous with causal powers, and it is these causal powers that interact to produce actual events. Each emergent property of an entity is the result of a mechanism that is characterized by the existence of a particular type of relations between particular types of parts - which we may call the structure of the entity. ${ }^{5}$ This is a recursive relation, in the sense that the parts of any given entity are also entities themselves, with their own emergent properties.

Thus, for example, the emergent properties of a biological cell are the result of the sorts of molecules of which it is composed and the set of relations between them that constitute them into this type of cell - but they are nevertheless the properties of the cell and not of the molecules, since these molecules would not possess those properties if they were not organized into this sort of cell. Similarly, the emergent properties of the molecules are the result of the sorts of atoms of which they are composed and the set of relations between those atoms that constitute them into this type of molecule.

Now this emergentist aspect of depth ontology is central for critical realists when we move from metaphysical concerns with the real in general to sociological concerns with the classic questions of social structure and agency. For critical realists, both social structures and human individuals are entities with emergent properties that arise from their ontological structure. Margaret Archer has developed the most influential version of the consequent claim that we must regard social structures as having causal powers in their own right. ${ }^{6}$ The key point is just the same as for emergent properties in general: social structures, like organizations and social 
institutions, are causally effective in their own right because their causal influence only arises when their parts (predominantly human individuals) are organized into this sort of structure. The individuals concerned would not have these causal powers if they were not organized into such structures, hence these are powers of the structure and not of the individuals who are its parts. It is the practice of exploring how these mechanisms are produced by emergence that gives critical realism its explanatory purchase.

Archer and Bhaskar have stressed that if structures do have emergent properties, then for analytical purposes we can treat individuals and structures as distinct (while recognizing that structures are 'activity dependent' - i.e. the product of the interacting individuals that form their parts). We can therefore analyse the interactions between them over time, in what Bhaskar calls the Transformational Model of Social Activity, and Archer the morphogenetic cycle (Archer 1995: 76-9; Bhaskar 1989: 76-7). Both models include two key moments. In the structural moment, individual action is influenced by the causal powers of social structures though not fully determined by it, since other interacting causal powers, including those of the individual concerned, interact in determining individual action. In the agential moment, individual actions contribute to reproducing and/or transforming the structure concerned (again interacting with other causal powers). The consequence is that critical realist social theory can recognize that both human individuals and social structures (and indeed entities of other kinds) have causal powers that are distinct from each other, and that both (or all) interact to determine social events - even though human individuals are the parts of the social structures concerned.

\section{Social structure in ANT}

By contrast, actor network theory shows little evidence of recognizing this second dimension of ontological depth. Indeed, it seems consistently hostile to the idea that social structure could be of any explanatory significance. Despite occasional heavily qualified acknowledgements that structural sociology may sometimes be of value (e.g. Latour 1996: 200; Latour 2005: 1, 226-7), the vast majority of ANT writing on the subject presents reasons why theorists should substitute explanatory references to individual actors for references to social structure. ${ }^{7}$ There seem to be two main arguments deployed to justify this. First, actor network theorists frequently argue that, 
however stable collective arrangements may have been in the past, today they are so fluid that to think in terms of stable social structures is obsolete. Second, they argue that whenever some structural influence is suggested, we can understand what is happening better by tracing the connections between individual actors than by attributing any causal influence to larger structures.

Both arguments can be introduced by looking at a paper by Michel Callon, cited as an exemplary case of ANT by Latour (Callon 1986; Latour 2005: 107). Callon argues for the methodological principle of free association, which avoids the use of a priori categories to refer to the identities of actors and the relationships between them. Instead these are 'allowed to fluctuate' and 'to take their course' as the actors concerned negotiate them in the course of the events being studied (Callon 1986: 222). For Callon, then, the technique of tracing particular connections follows from the need to capture the fluidity of the 'alliances' developed during the period.

Law develops this argument a step further: for him, the social is not only rapidly changing, but also sometimes indefinite in form (Law 2004: 6). To put it graphically, 'in this way of thinking the world is not a structure, something we can map with our social science charts. We might think of it, instead, as a maelstrom or a tide-rip. Imagine that it is filled with currents, eddies, flows, vortices, unpredictable changes, storms, and with moments of lull and calm' (Law 2004: 7).

Latour, on the other hand, does not rest his argument on the instability of structures and thus on some novel feature of certain parts of the contemporary world. He argues that conventional sociology - the 'sociology of the social' (Latour 2005: 9) - takes for granted the existence of 'a stabilized state of affairs, a bundle of ties that, later, may be mobilized to account for some other phenomenon' (Latour 2005: 1) and treats these as a 'reservoir of forces' (Latour 2005: 35) that can be drawn on to explain human behaviour. He ascribes a thoroughly static view of structure to this approach: 'for sociologists of the social, the rule is order while decay, change, or creation are the exceptions' (Latour 2005: 35). And he suggests that this becomes a way to ascribe explanatory force to social structures without justifying such ascriptions: 'hidden variables have become packaged in such a way that there is no control window to check what is inside' (Latour 2005: 50). Overall, 'The social of sociologists thus appears ... [as] a superfluity, a purely redundant rear-world adding 
nothing to the real world except artificial conundrums - just like the ether before relativity theory' (Latour 2005: 107).

For Latour, the idea that power can come from some central social source and then diffuse through society is more or less incoherent. Instead, he argues, influence passes along chains of agents, 'each of whom 'translates' it in accordance with his/her own projects... In the translation model the study of society therefore moves from the study of the social as this is usually conceived, to a study of methods of association' (Latour 1986: 264). ${ }^{8}$ Thus, instead of the sociology of the social, Latour proposes a 'sociology of associations' (Latour 2005: 9), a sociology that traces these associations. In this model, any collective influence is always passed through chains of mediators, who actively shape and translate that influence in ways that correspond to their own projects and purposes, as opposed to intermediaries, who transmit tokens of authority unchanged (Latour 2005: 39). In the sociology that results, 'there is no society, no social realm, and no social ties, but there exist translations between mediators that may generate traceable associations' (Latour 2005: 108-9).

On occasion Latour talks as if there are nevertheless some social entities that should feature in sociology, although we should always begin by tracing the associations. For example, he writes 'Although there is indeed, in every interaction, a dotted line that leads to some virtual, total, and always pre-existing entity, this is just the track that should not be followed, at least for now' (Latour 2005: 166). Here Latour talks as if he were just deferring the moment at which structure is recognized, yet he never seems to finally arrive at this moment.

It is only in the hands of the actors themselves that social structures seem to be allowed, and sociologists must content themselves with 'mapping the many contradictory ways in which social aggregates are constantly evoked, erased, distributed, and reallocated' (Latour 2005: 41). And: 'it is not the sociologist's job to decide in the actor's stead what groups are making up the world and which agencies are making them act' (Latour 2005: 184).

Even when the actors themselves do perceive some structural influence, Latour seeks to explain this influence in terms of individual mediators. Thus, in the project that is the subject of his book Aramis, the few elected officials recruited by the project certainly don't count as Politics; the economists who calculate profit margins don't constitute Economics; the handful of engineers who evaluate Aramis' technological refinement certainly 
don't equate with Technology. The impression of a context that surrounds the project comes from the fact that one forgets to count the handful of mediators who speak in the name of money, Official Bodies, chips, or voters (Latour 2005: 134).

ANT therefore presents what critical realists would call a flat ontology in not just one but two respects: in addition to its neglect of realities beyond the empirical domain, it also strives to ignore the existence of emergent social structures. Indeed Latour himself entitles a chapter 'How to Keep the Social Flat' (Latour 2005). Higher structural levels appear only as figments of actors' imaginations, as constructions they make of their personal contexts, which in reality can be reduced to handfuls of mediators with whom they associate.

\section{A realist response}

It's rarely clear which sociologists Latour is criticising when he portrays - one might say caricatures - a 'sociology of the social'. No doubt there are still sociologists who uncritically ascribe causal powers to social structures without examining how they are produced by the interaction of human agents. But it should already be clear that at least some parts of Latour's critique do not apply to the critical realist account of social structure.

Most obviously, the critical realist model sees social structures as being composed of human individuals, and as being reproduced and/or transformed by the actions of those individuals. Both Bhaskar and Archer's models of structure not only place structural change in the centre of their accounts, but even give it an explicit role in the names they apply to these models: both the 'genetic' in Archer's morphogenetic cycle and the 'Transformational' in Bhaskar's TMSA refer to the dynamic of structural change. In these models, structures are constantly made and re-made through human agency. This allows for structural fluidity, but also for structural stability. Indeed, ANT's refusal to theorize structural stability must count as one of its gravest weaknesses; much of contemporary society may well be fluid, but there are still massive stabilities, over a variety of time frames, which are enormously important in contemporary society. Many of the most significant social structures in Western society, for example, simultaneously demonstrate aspects that have evolved over time and aspects that remain more or less unchanged, such as the institutions of contract, property, and monogamy, and organizations such as states, schools, and 
armies. No social theory can be adequate unless it can theorize both change and stability in social structures.

On the other hand, I will argue that ANT's techniques of tracing the connections at the level of individual actors have a great deal to contribute to such a theory. Indeed, critical realists need to do more of this: the realist models of social structure recognize the important role of individuals in principle, but relatively little work has been done in the $\mathrm{CR}$ tradition on tracing the connections between individuals and social structure in practice. Tracing these connections, however, does not necessarily lead to 'keeping the social flat'. In an emergentist understanding of social structure, we need to trace them not in order to substitute individual associations for social structure, but instead to identify the mechanisms that underlie social structures; the kinds of relations between individuals that lead to emergent properties at the structural level. A realist sociology of associations would trace associations in order to explain structure, not in order to explain it away.

For this to work, however, we must recognize that social structures are not to be equated in general with 'the structure of the social', in which the social stands for society as a whole. Social structures, in the realist model, are specific collectives with specific properties. Most obviously, organizations are social structures, with causal powers that arise from the way that their members are related by occupying organizationally-defined roles (see Elder-Vass 2007a). A little more subtly, normative communities are social structures, with the power to institutionalize our behaviour (see Elder-Vass 2008). This tradition, then, has no truck with the sort of invocation of an amorphous 'social' that Latour criticizes with his portrait of 'the sociology of the social'.

Intriguingly, ANT itself seems occasionally to invoke more specific social structures of the type theorized by realists, despite its anti-structural rhetoric. Latour, for example, seems happy to treat the Aéroport de Paris (the organization, it would seem, rather than, or perhaps including, the physical airport) as an actor in the story of Aramis (Latour 1996: 57). And Law seems to refer to the hinterland of scientific knowledge and instrumentation in terms that seem remarkably similar to Bhaskar's transformational model of social activity - this hinterland has a formative impact on scientific action, and that action in turn reproduces and/or transforms the hinterland (Law 2004: 28-32). What is absent from such treatments, however, is any recognition 
that in citing these organizations and hinterlands as causal contributors ANT is moving beyond a flat social ontology.

If they wish to preserve this flat ontology, as it seems they do, actor network theorists have to reduce these structural effects to those of individuals. A classic example is provided by Latour when he discusses the importance of commitments to the continuation of a technological project. A government official, according to Latour, 'may speak for all French people', or for a particular department, or some part of a department, or just himself (Latour 1996: 44). This, according to Latour, is to be accounted for as a variation in the relative size or representativeness of an individual actor. Similar arguments apply to the representatives of the other organizations involved. And so, at a stroke, the causal contribution of the organizations that fund the entire project is reduced to the effects of a few individuals.

But it is perfectly obvious that these individuals could not commit these funds if they did not occupy particular roles as parts of these organizations. No organization: no funds: no project. In other words, we must recognize that sometimes when individuals act, they do so as representatives of larger structures; that their action is not the action of an individual alone, but at least in part the action of a structure. This need not reduce those individuals to mere intermediaries: the structure concerned will only ever co-determine their actions in conjunction with other causal factors. But nor does it alter the fact that the individual sometimes deploys causal powers of the whole organization, and not just those of their own person.

Sociology, then, cannot dispense with structure, and critical realism provides an account of structure that recognizes its relation with individual agency without reducing it entirely to such agency. Critical realism would benefit from devoting more attention to tracing the associations that make this possible - but this is entirely compatible with its ontological commitments. Actor network theory, on the contrary, could only recognize the causal contribution of social structure by abandoning its ontological commitments.

\section{Actors and agency}

ANT's denial of structural power places the burden of sociological explanation on the causal influence of actors, as we have seen in Latour's emphasis on the role of mediators in the chains of translation through which power operates. One of ANT's 
characteristic theoretical moves, however, is to widen the category of 'actors' beyond human agents, extending it to include non-human objects too. Such objects are 'participants in the course of action' because they 'make a difference in the course of some other agent's action' (Latour 2005: 70-1). The point of their argument is a valuable one: sociologists have tended to neglect the causal influence of non-human objects, focusing instead on human agents and social structures that are in some sense a product of human agents. This is particularly problematic when we are dealing with the areas of science and technology, given that these are largely concerned with the understanding and manipulation of non-human objects - though one might make a similar argument with regard to almost every field of human activity.

ANT's technique for redressing the balance is to call for non-human actors to be treated symmetrically with human actors (Callon 1986: 200; Law 2004: 102). Callon's paper on the scallops and fishermen of St Brieuc Bay is paradigmatic here. The paper tells the story of a group of marine biologists ('the researchers') who are trying to maintain scallop stocks in the face of over-fishing. What is most striking about this paper is that Callon constantly seeks to treat the scallops and the fishermen in similar terms. Thus, for example, he argues that the researchers 'join forces with the scallops, the fishermen, and their colleagues' (Callon 1986: 208), and that 'both the fishermen and the scallops end up being represented by the three researchers who speak and act in their name' (Callon 1986: 216). This is an intriguing provocation, but not an unreasonable one.

Yet some of Callon's other attempts to treat scallops and fishermen symmetrically are frankly bizarre - or at least appear to be so in the standard English translation. ${ }^{9}$ For example: 'In fact, the three researchers will have to lead their longest and most difficult negotiations with the scallops' (Callon 1986: 211). 'As we have seen, the negotiations between the scallops and the researchers revolve around one question: how many larvae can be trapped?' (Callon 1986: 215). And 'The scallops become dissidents. The larvae which complied are betrayed by those they were thought to represent' (Callon 1986: 220).

Latour, too, adopts this sort of symmetry:

To get Aramis past the paper phase into the prototype phase, you have to get a whole list of things interested in the project: a motor, an ultrasound sensor, assorted software, electric currents, concrete-and-steel sandwiches, switching arms... The same sort of involvement that has to be solicited from [various organizations] now has to be solicited from motors, activators, doors, cabins, 
software, and sensors. They, too, have their conditions; they allow or forbid other alliances (Latour 1996: 57).

As a literary device, such metaphors are stimulating. As a device for provoking the recognition of a gap in conventional sociological reasoning, they are effective. As a methodological requirement for sociological work, they are thoroughly misguided. ${ }^{10}$ Scallops don't negotiate, represent, or betray. Motors don't become interested in projects or allow or forbid anything. (It is possible, of course, that Latour does not intend us to take such claims literally - see my earlier footnote on translation issues. If this is so, then my comments here are only required as a warning to literalminded Anglophone readers like myself).

For critical realists, scallops, motors, and other non-human objects are significant in sociological explanations because they have causal powers - just as human agents are significant in sociological explanations because they have causal powers. ${ }^{11}$ But scallops have different causal powers from humans, and different causal powers from motors. Scallops have the power to attach themselves to rocks or to the collectors used by researchers; they do not have the power to negotiate. Motors have the power to drive vehicles in certain conditions (but not in others); they do not have the power to be interested, to allow, to forbid. These are all powers that depend upon mechanisms possessed by humans and not by non-human objects. The differences in structure between these different sorts of entities lead to them possessing different capabilities, and the terms we use in describing them need to be sensitive to the capabilities they possess. We achieve symmetry in the treatment of human and nonhuman actors, not by treating them all in the same terms, but by treating each in the terms that are appropriate to its own particular structure and properties.

Indeed, one of the merits of critical realism is that it applies just this sort of symmetry to the treatment of human agents and social structures. In critical realism's emergentist ontology, as we have seen, we recognize that social structures are composed primarily of human beings, and accept the obligation to demonstrate how it is that structures of this sort could have the particular powers that we ascribe to them - by tracing the connections, the mechanisms, through which these powers are generated. When it comes to human agents, critical realism accepts just the same obligation: we need to recognize that human beings have biological (and particularly neurological) structures from which our capabilities arise, and hence we cannot coherently ascribe powers to human beings unless we are also prepared to examine 
how it is that these structures can produce these powers. Human agency, in other words, is no less problematic than social structure, and requires the same sort of attention to explaining how it works.

This is a massive subject, and no theorist can be expected to cover it in its entirety, but a major contribution to its understanding has already been made in the work of Margaret Archer, whose recent books on agency (Archer 2000; Archer 2003; Archer 2007) examine the way that each of us develops a series of identities and a particular style of reflexivity. Elsewhere I have examined how the emergence of human beliefs and dispositions from neurological underpinnings can help us to understand human action (Elder-Vass 2007b). And there is a vast reservoir of work from other traditions that can be integrated into the explanation of human agency in realist and emergentist terms.

But ANT seems largely to ignore the need for any such work. Its desire for symmetry seems oddly circumscribed. Latour has opened up the question of action occasionally; but his approach is primarily to place the contributors to action outside the actors, rather than examining how the actors themselves could ever come to act: 'An "actor"... is not the source of an action but the moving target of a vast array of entities swarming toward it' (Latour 2005). And 'Humans and non-humans take on form by redistributing the competences and performances of the multitude of actors that they hold on to and that hold on to them' (Latour 1996: 225). When he does begin to look inside the actor, it is not to examine the inherent structure, but to suggest that contemporary human agents are built up to a state of completeness by plugging in circulating entities - 'subjectifiers, personnalizers, or individualizers' - that he compares to the plug-ins, applets, and patches we can obtain for our computer software from the Internet (Latour 2005: 207). And 'Subjectivity seems also to be a circulating capacity, something that is particularly gained or lost by hooking up to certain bodies of practice' (Latour 1999: 23).

There is no attempt here to explain how humans can be actors at all, no attempt to trace the connections underlying them. This seems radically contradictory to the rhetoric with which social structure is approached: 'When we list the qualities of an ANT account, we will make sure that when agencies are introduced they are never presented simply as matters of fact but always as matters of concern, with their mode of fabrication and their stabilizing mechanisms clearly visible' (Latour 2005: 
120). Yet the agency of human individuals is largely taken for granted; symmetry, it seems, does not apply here.

I can only speculate on why this might be; but for a realist an obvious answer is waiting in the wings: ANT's realism is not just actualist but also empiricist. It uncritically accepts the reality of the objects and capabilities that we can perceive directly with our own senses, and largely refuses to believe in the reality of anything else. So human agents and non-human objects are so obvious that we can take them for granted; but for actor network theory social structure does not exist at all.

\section{Conclusion}

This paper has sought to engage openly and constructively with actor network theory from a critical realist perspective. There are two strands to its argument. On the one hand, I have sought to identify things that realists can learn from actor network theory. On the other, this paper has presented a robust critique of the limitations placed on actor network theory by its ontological commitments, and in particular by the multi-dimensional absence of a depth ontology. Both sets of conclusions derive from the analysis of three provocations offered by actor network theory.

The first provocation: that science creates the world it describes. This is superficially a constructionist claim, and as such the critical realist reflex would be to reject it out of hand. And yet there are a great many things that humans do construct, including many of the actualities implicated in science. This does not mean that these things are not real, and one of the challenges for critical realism is to develop a more subtle account of the relation between reality and social construction. Yet actor network theory's own account of this relation is fatally flawed by its empiricism. Not only does it fail to recognize the existence of mechanisms that are independent of and anterior to scientific investigations; it often fails even to recognize the existence of actualities prior to their observation and description by professional observers.

The second provocation: that social explanations should always be framed in terms of associations between individual actors. There is a great deal of value in ANT's demand that we trace the associations between actors; we cannot give a full account of the workings of social structures unless and until we can explain how it is that these structures are produced by associations between actors. Critical realists need to do more of this, to demonstrate the value of an emergentist account of social 
structure in practice, and not just from a more abstract perspective. Yet once again, actor network theory offers only a provocation and not a viable alternative, and again it is because of the absence of depth in its ontology. This absence obscures from actor network theory the possibility that social structures can be causally effective in their own right, even though they are composed of human actors, and the possibility that when humans act, it is sometimes a case of structures acting through them.

The third provocation: that human and non-human actors should be treated symmetrically. This is a valuable reminder, still not taken to heart by many sociologists, that non-human objects have causal powers that make a vital contribution to the causation of social events. But critical realism's ontology provides a much more appropriate form of symmetry than the self-consciously naïve application of the same terminology to human and non-human actors advocated by actor network theory. Critical realism's symmetry appears in the recognition that it is the possession of causal powers that is held in common by these two groups of actors, while the particular causal powers (and hence the particular terminology appropriate to their description) vary depending on the underlying structure and mechanisms of each type of actor. Once again, it seems that actor network theory is hampered by its failure to see beyond the empirical face of reality.

Given the ontological chasm between these two traditions, synthesis appears out of the question, but I hope this paper has demonstrated that constructive critical engagement is worthwhile.

\section{Bibliography}

Archer, M. 1995 Realist Social Theory: The Morphogenetic Approach, Cambridge: Cambridge UP.

Archer, M. 2000 Being Human: The Problem of Agency, Cambridge: Cambridge UP. Archer, M. 2003 Structure, Agency, and the Internal Conversation, Cambridge: Cambridge UP.

Archer, M. 2007 Making Our Way through the World: Human Reflexivity and Social Mobility, Cambridge: Cambridge UP.

Benton, T. 1991 'Biology and Social Science', Sociology 25(1): 1-29.

Bhaskar, R. 1978 A Realist Theory of Science, 2nd Edition, Hassocks: Harvester Press.

Bhaskar, R. 1989 Reclaiming Reality: A Critical Introduction to Contemporary Philosophy, London: Verso. 
Bhaskar, R. [1979] 1998 The Possibility of Naturalism, 3rd Edition, London: Routledge.

Callon, M. 1986 'Some Elements of a Sociology of Translation: Domestication of the Scallops and the Fishermen of St Brieuc Bay' in J. Law (ed.) Power, Action and Belief, London: Routledge \& Kegan Paul.

Dean, K., Joseph, J. and Norrie, A. 2005 'Editorial: New Essays in Critical Realism', New Formations: 7-26.

Elder-Vass, D. 2005 'Emergence and the Realist Account of Cause', Journal of Critical Realism 4(2): 315-38.

Elder-Vass, D. 2007a 'For Emergence: Refining Archer's Account of Social Structure', Journal for the Theory of Social Behaviour 37(1): 25-44.

Elder-Vass, D. 2007b 'Reconciling Archer and Bourdieu in an Emergentist Theory of Action', Sociological Theory 25(4): 325-46.

Elder-Vass, D. 2007c 'Re-Examining Bhaskar's Three Ontological Domains: The Lessons from Emergence' in C. Lawson, J. Latsis and N. Martins (eds.) Contributions to Social Ontology, London: Routledge.

Elder-Vass, D. 2008 'Integrating Institutional, Relational, and Embodied Structure: An Emergentist Perspective', British Journal of Sociology 59(2): 281-99.

Foucault, M. 2000 'The Subject and Power' in K. Nash (ed.) Readings in Contemporary Political Sociology, Malden, MA: Blackwell.

Garfinkel, H. 1967 Studies in Ethnomethodology, Englewood Cliffs, N.J.: PrenticeHall.

Latour, B. 1986 'The Powers of Association' in J. Law (ed.) Power, Action and Belief, London: Routledge \& Kegan Paul.

Latour, B. 1996 Aramis: Or the Love of Technology, Cambridge, Mass. ; London: Harvard University Press.

Latour, B. 1999 'On Recalling ANT' in J. Law and J. Hassard (eds.) Actor Network Theory and After, Oxford: Blackwell.

Latour, B. 2005 Reassembling the Social, Oxford: Oxford University Press.

Latour, B. and Woolgar, S. 1979 Laboratory Life: The Social Construction of Scientific Facts, Beverly Hills: Sage Publications.

Latour, B. and Woolgar, S. 1986 Laboratory Life: The Construction of Scientific Facts, 2nd Edition, Princeton, N.J.: Princeton University Press.

Law, J. 1999 'After ANT: Complexity, Naming and Topology' in J. Law and J. Hassard (eds.) Actor Network Theory and After, Oxford: Blackwell.

Law, J. 2004 After Method: Mess in Social Science Research, London: Routledge. Mol, A. 2002 The Body Multiple: Ontology in Medical Practice, Durham NC: Duke UP.

Mutch, A. 2002 'Actors and Networks or Agents and Structures: Towards a Realist View of Information Systems', Organization 9(3): 477-96.

Pawson, R. 1989 A Measure for Measures, London: Routledge.

\footnotetext{
${ }^{1}$ An earlier version of this paper was presented to the British Sociological Association's Realism Study Group, and this version has benefited from the comments made there, particularly by Dave Byrne, and elsewhere by Andrew Sayer. Malcolm Fowles (via Ivan Horrocks) has made me aware of important doubts concerning the translation into English of some of the work discussed below.

${ }^{2}$ For example, Mutch suggests that ANT has turned away from the excesses of the linguistic turn since its early years (Mutch 2002: 486).
} 
${ }^{3}$ Bhaskar's argument is discussed in much more depth in (Elder-Vass 2005) and (Elder-Vass 2007c).

${ }^{4}$ This is particularly clearly expressed in (Pawson 1989: 106-7).

${ }^{5}$ This is therefore a relational version of the concept of emergence, in which it is possible to explain an entity's emergent properties in terms of the properties of its parts and the relations between them, but not to eliminate the whole entity from the explanation as a result. Many philosophical accounts of emergence adopt a strong version of emergence, in which it is not possible to explain emergent properties in terms of lower level parts and relations, but examples of such emergence are hard to find. ${ }^{6} \mathrm{I}$ have sought to refine her argument in (Elder-Vass 2007a).

${ }^{7}$ ANT stresses that 'actors' may be non-human as well as human. While I neglect this argument in the present section, I will return to it in the section on agency.

${ }^{8}$ Note the similarities to Foucault's concept of power as action upon the action of others (Foucault 2000: 20). I am grateful to Andrew Sayer for pointing this out.

${ }^{9}$ To be fair to Callon, I should point out that this translation may not be reliable. It is possible, for example, that in the quotes given here a more accurate translation would be 'interactions' rather than 'negotiations'. Here and elsewhere, Malcolm Fowles has suggested, "alternative English translations exist which avoid the sense of volition by inanimate objects" (personal communication). If Callon has been misrepresented, my critique of the anthropomorphisation of his scallops would be unnecessary, except as a warning to readers of the translation.

${ }^{10}$ See (Mutch 2002: 489-90) for an earlier critical realist response that both recognises the need to "render technology a little more visible" and rejects ANT's version of symmetrical treatment of human and non-human actors.

${ }^{11}$ Amongst critical realists, Ted Benton in particular has argued against dualistic oppositions between nature and society in the social sciences (e.g. Benton 1991: 25). 